\title{
A global assessment of cancer genomic alterations in epigenetic mechanisms
}

\author{
Muhammad A Shah ${ }^{1 \dagger}$, Emily L Denton ${ }^{1,4 \dagger}$, Cheryl H Arrowsmith ${ }^{1,2}$, Mathieu Lupien ${ }^{2}$ and Matthieu Schapira ${ }^{1,3^{*}}$
}

\begin{abstract}
Background: The notion that epigenetic mechanisms may be central to cancer initiation and progression is supported by recent next-generation sequencing efforts revealing that genes involved in chromatin-mediated signaling are recurrently mutated in cancer patients.

Results: Here, we analyze mutational and transcriptional profiles from TCGA and the ICGC across a collection 441 chromatin factors and histones. Chromatin factors essential for rapid replication are frequently overexpressed, and those that maintain genome stability frequently mutated. We identify novel mutation hotspots such as K36M in histone $\mathrm{H} 3.1$, and uncover a general trend in which transcriptional profiles and somatic mutations in tumor samples favor increased transcriptionally repressive histone methylation, and defective chromatin remodeling.

Conclusions: This unbiased approach confirms previously published data, uncovers novel cancer-associated aberrations targeting epigenetic mechanisms, and justifies continued monitoring of chromatin-related alterations as a class, as more cancer types and distinct cancer stages are represented in cancer genomics data repositories.
\end{abstract}

Keywords: Epigenetics, Pan-cancer, Chromatin, Mutation, Amplification, RNA-seq

\section{Background}

Epigenetic control of gene expression dictates cell fate in health and disease, and dysregulation of epigenetic signals is associated with cancer [1,2]. Two observations support pharmacological targeting of the 'cancer epigenome' [1]: (1) some cancer-associated epigenetic aberrations drive cancer initiation or progression; and (2) unlike genetic information, epigenetic states are reversible. Pharmacological agents targeting with little specificity DNA methylation and histone de-acetylation have been approved for the treatment of myelodysplastic syndrome and lymphoma respectively $[3,4]$, and compounds targeting bromodomain-containing proteins and protein methyltransferases have recently advanced to clinical trials $[5,6]$. Cancer associated overexpression, mutation, or aberrant recruitment of chromatin factors (defined here as proteins that participate in the chemical modification of DNA, histones, or control nucleosome occupancy),

\footnotetext{
* Correspondence: matthieu.schapira@utoronto.ca

${ }^{\dagger}$ Equal contributors

${ }^{1}$ Structural Genomics Consortium, University of Toronto, MaRS Centre, South

Tower, 101 College Street, Toronto M5G 1L7, ON, Canada

${ }^{3}$ Department of Pharmacology and Toxicology, University of Toronto, 1

King's College Circle, Toronto M5S 1A8, ON, Canada

Full list of author information is available at the end of the article
}

represent emerging opportunities for cancer therapy. For instance, inhibitors of EZH2 - a histone 3 lysine 27 (H3K27) methyltransferase that is overexpressed in a number of solid tumors and is the site of recurrent gainof-function mutations in lymphoma - are raising considerable interest as potential anti-cancer agents, and have recently advanced to the clinic [5].

Chromosomal aberrations and altered expression of chromatin factors that are recurrent in specific cancer types have been reported in the literature, some extensively, and recently reviewed [2,7-9]. Out of the recent compilation of the 58 most frequently mutated genes in cancer [10], we find that 16 are chromatin factors. These aberrations can lead to the deregulation of chromatin patterns controlling hundreds of target genes, as recently reviewed by Plass et al. [11]. Pan-cancer analyses of the human genome's mutational landscape were also recently reported [12-14]. Here, we present a pan-cancer analysis focused on proteins that shape the human epigenome based on the chromosomal and transcriptional landscape of tumor samples from cancer patients available from The Cancer Genome Atlas (TCGA) [15] and the International Cancer Genome Consortium (ICGC) [16]. We took an unbiased approach and focused on cancer types with large 
numbers of patient samples, but excluding genomes that are extensively rearranged. This systematic and integrated approach identifies many oncogenic aberrations already recorded in the literature, but also uncovers novel alterations recurrently affecting chromatin factors in specific cancer types. Overall our results provide novel insight into the cancer epigenome revealing a tendency toward alterations predicted to result in greater transcriptional repression, decreased transcriptional activation and reduced chromatin remodeling.

\section{Results}

\section{Study design}

Chromatin factors were divided into protein families: protein methyltransferases (PMTs), lysine demethylases (KDMs), histone acetyltranferases (HATs), histone deacetylases (HDACs), DNA methyltransferases (DNMTs), methylcytosine oxidases (TETs), bromodomain containing proteins (BRDs), Royal family of methyl-lysine readers (Kme readers), PHD finger containing proteins (PHDs), and methyl-cytosine binding proteins (MBDs). Some of the members of these protein families are not known to participate in epigenetic signaling, but we followed a target-class approach and included these genes in the analysis. Components of ATP-dependent chromatin remodeling complexes [17] were also added to the analysis as well as histones and their chaperones. Finally, $I D H 1$ and $I D H 2$, two genes that control cellular levels of 2-hydroxyglutarate (an inhibitor of lysine and DNA de-methylases) were included [18], for a total of 441 genes (Additional file 1: Table S1). All pre-processed, validated mutation, and RNAseq expression data affecting these genes in tumor samples were extracted from TCGA (level 3 and 4) and the ICGC (mutation data only - level 3) and grouped by cancer type (Additional file 2: Figure S1). Changes in expression levels and mutation were measured relative to matched normal samples from the same patient. Cancer genomes with unusually high mutation rates (and therefore more passenger mutations) were excluded from the analysis (see Methods section for details). Only cohorts with more than 100 patients passing this filter were considered in order to calculate mutation frequencies. Frequencies of change in gene expression were calculated from cohorts of more than 30 patients. Chromosomal translocations are not included in our analysis. These are directly accessible from literature-based resources such as the Mitelman or COSMIC databases, but we made a deliberate choice here of avoiding data that has been extracted from the literature.

\section{Uneven deregulation of epigenetic target classes in cancer} As shown in Additional file 2: Figure S1 and Table 1, our analysis retrieved a number of known cancer-associated aberrations in chromatin factors. For instance, EZH2 appears as the most frequently overexpressed protein methyltransferase. We find that this gene is not only overexpressed in breast and prostate cancer, as extensively published [19], but also ranks number 44 and 94 among the most frequently overexpressed genes in liver hepatocellular carcinoma and lung squamous cell carcinoma, respectively. Other examples include recurrent mutations of the chromatin remodeling protein ATRX in lower grade glioblastoma ( $40 \%$ of patient) [20], or DNMT3A and TET 2 in acute myeloid leukemia (25\% and $8.6 \%$ of patients, respectively) [21,22], mutations of the H3K4 methyltransferase MLL3 in $7.7 \%$ of breast cancer patients [23], or mutations of the bromodomain containing protein PBRM1 in $28.5 \%$ of kidney renal clear cell carcinoma [24].

Our analysis also reveals previously unreported observations. The PRDM sub-group of PMTs is overwhelmingly repressed across multiple cancer types, suggesting tumor suppressor activity, but PRDM12 is among the most overexpressed genes in prostate adenocarcinoma (log2 tumor versus matched control $>1$ in $66 \%$ patients). We also note that PRDM12 is overexpressed in 21 out of 22 colon adenocarcinoma patients (this patient cohort is not presented in our analysis because its size does not meet our criteria for statistical significance (cohort size $<30$ patients), but this exceptional ratio of $95 \%$ is still worth mentioning). The arginine methyltransferase PRMT8 is overexpressed in $68 \%$ of thyroid carcinoma (Additional file 2: Figure S1A). Another PMT, MLL2, and the HAT EP300 are found mutated in $18 \%$ and $7.8 \%$ of head and neck tumors, respectively (Table 1). Interestingly, L3MBTL4, a methyl-lysine reader, is one of the most repressed chromatin factors across all cancer types examined.

It has been argued that epigenetic mechanisms are at the heart of cancer biology [9], and it is reasonable to ask whether protein families that control epigenetic signaling represent promising target classes for cancer prevention and treatment. To indirectly address this question, we compared the transcriptional and mutational landscapes of our 441 chromatin genes from which were excluded histones and their chaperones (totaling 359 genes) with those of the human kinome composed of 504 kinases (a validated target class), and five independent sets of 359 random genes (excluding kinases and chromatin factors) (Figure 1). We find that the frequency of altered expression in tumor samples is identical for kinases and random genes, but significantly lower for chromatin factors. Since chromatin factors contribute to regulation of the expression profile of the entire genome, small variations in the expression level of chromatin factors may result in greater changes in the expression level of target genes. Inversely, we find that chromatin factors are more frequently mutated in tumor samples than random genes (Figure 1). Again, the rationale here may be that since chromatin factors control the transcriptional profile of the cancer genome, mutations 
Table 1 Most frequently mutated or over/under-expressed chromatin factors in cancer

\begin{tabular}{|c|c|c|c|c|c|c|c|c|c|c|c|}
\hline Gene & Cancer & $\begin{array}{l}\text { Mutated } \\
(\%)\end{array}$ & $q$ value & Gene & Cancer & $\begin{array}{l}\text { Overexpressed } \\
(\%)\end{array}$ & $\begin{array}{l}\text { Rank (out } \\
\text { of } 20,544)\end{array}$ & Gene & Cancer & $\begin{array}{l}\text { Underexpressed } \\
\text { (\%) }\end{array}$ & $\begin{array}{l}\text { Rank (out } \\
\text { of } 20,544 \text { ) }\end{array}$ \\
\hline ATRX & LGG & 39.8 & $1.82 \mathrm{E}-11$ & HJURP & PRAD & 88 & 3 & PRDM16 & KIRP & 100 & 14 \\
\hline ARID1A & UCEC & 32.3 & $8.11 \mathrm{E}-12$ & UHRF1 & BRCA & 94.7368 & 7 & PRDM16 & KIRC & 95.8904 & 40 \\
\hline PBRM1 & $\mathrm{KIRC}$ & 28.5 & $1.76 \mathrm{E}-11$ & TDRD1 & PRAD & 84 & 14 & KAT2B & HNSC & 82.9268 & 55 \\
\hline DNMT3A & LAML & 25.4 & 3.96E-12 & DPF1 & HNSC & 87.8049 & 25 & JMJD5 & LIHC & 88 & 56 \\
\hline MLL2 & LUSC & 19.1 & $6.39 \mathrm{E}-05$ & HJURP & BRCA & 91.2281 & 29 & TDRD10 & LUSC & 100 & 57 \\
\hline ARID1A & STAD & 18.1 & 2.63E-11 & HJURP & LUAD & 94.7368 & 31 & MECOM & KIRC & 95.8904 & 62 \\
\hline MLL2 & HNSC & 17.7 & $1.94 \mathrm{E}-11$ & HJURP & LIHC & 96 & 34 & L3MBTL4 & PRAD & 76 & 73 \\
\hline CHD4 & UCEC & 13.3 & 0.000958 & ASF1B & BRCA & 91.2281 & 37 & ASXL3 & THCA & 78.7879 & 81 \\
\hline STK31 & SKCM & 11.9 & 0.049702 & UHRF1 & KIRP & 90 & 37 & CECR2 & THCA & 80.303 & 83 \\
\hline NSD1 & HNSC & 10.8 & 1.89E-11 & ORC1 & LIHC & 94 & 40 & ZCWPW2 & HNSC & 80.4878 & 84 \\
\hline SETD2 & $\mathrm{KIRC}$ & 9.8 & $1.76 \mathrm{E}-11$ & EZH2 & $\mathrm{LIHC}$ & 94 & 44 & ZGPAT & LIHC & 82 & 141 \\
\hline TET2 & LAML & 8.6 & 2.42E-11 & ASF1B & KIRP & 90 & 45 & TDRD10 & BRCA & 85.0877 & 154 \\
\hline EP300 & HNSC & 7.8 & 0.008196 & HJURP & LUSC & 100 & 47 & MECOM & KIRP & 93.3333 & 162 \\
\hline MLL3 & BRCA & 7.7 & 1.95E-11 & UHRF1 & LUSC & 100 & 68 & ACTA1 & PRAD & 70 & 194 \\
\hline SMARCA4 & LUAD & 7.4 & 2.99E-08 & ORC1 & LUAD & 92.9825 & 72 & CBX7 & BRCA & 83.3333 & 218 \\
\hline SETD2 & LUAD & 7 & 0.006858 & ORC1 & LUSC & 100 & 79 & TDRD9 & THCA & 71.2121 & 261 \\
\hline KDM5C & $\mathrm{KIRC}$ & 5.8 & $3.75 \mathrm{E}-11$ & ASF1B & LUSC & 100 & 90 & TDRD6 & BRCA & 81.5789 & 277 \\
\hline ARID1A & LUAD & 5.7 & 0.001823 & $\mathrm{EZH} 2$ & LUSC & 100 & 94 & CHD5 & PRAD & 68 & 277 \\
\hline SMARCA4 & LGG & 4.5 & 0.035502 & UHRF1 & LUAD & 89.4737 & 101 & KIAA1045 & BRCA & 80.7018 & 298 \\
\hline KDM5C & LUAD & 4.4 & 0.091808 & HIST1H3D & BRCA & 85.9649 & 102 & CBX7 & LUAD & 85.9649 & 342 \\
\hline ARID1A & BRCA & 2.9 & 0.000117 & TCF19 & LIHC & 88 & 102 & SCML2 & THCA & 69.697 & 344 \\
\hline PHF6 & LAML & 2.5 & 0.001759 & HJURP & KIRP & 83.3333 & 107 & L3MBTL4 & BRCA & 79.8246 & 346 \\
\hline HIST1H1B & HNSC & 2.3 & 0.084637 & CECR2 & PRAD & 72 & 107 & DPF3 & LIHC & 72 & 364 \\
\hline \multirow[t]{2}{*}{ HIST1H3B } & BRCA & 1.1 & $9.81 \mathrm{E}-05$ & $\mathrm{HIST} 1 \mathrm{H} 3 \mathrm{H}$ & BRCA & 85.9649 & 109 & CECR2 & KIRC & 83.5616 & 388 \\
\hline & & & & UHRF1 & LIHC & 88 & 109 & PRDM16 & LUSC & 92 & 410 \\
\hline
\end{tabular}

Values indicate the frequency of cancer patients where a gene is mutated (non-silent mutations only), where Log2(mRNA tumor/matched control) $>1$ for overexpression,

or $<-1$ for underexpression. All data were extracted from TCGA and the ICGC. Patient cohorts are greater than 30 for overexpression and 100 for mutations. Hypermutated genomes and other sources of noise were excluded (as detailed in the Methods section). $q$ value is a measure of the $P$ value adjusted for false discovery rate. Ranks indicate the number of genes more frequently over- or underexpressed in the human genome. 


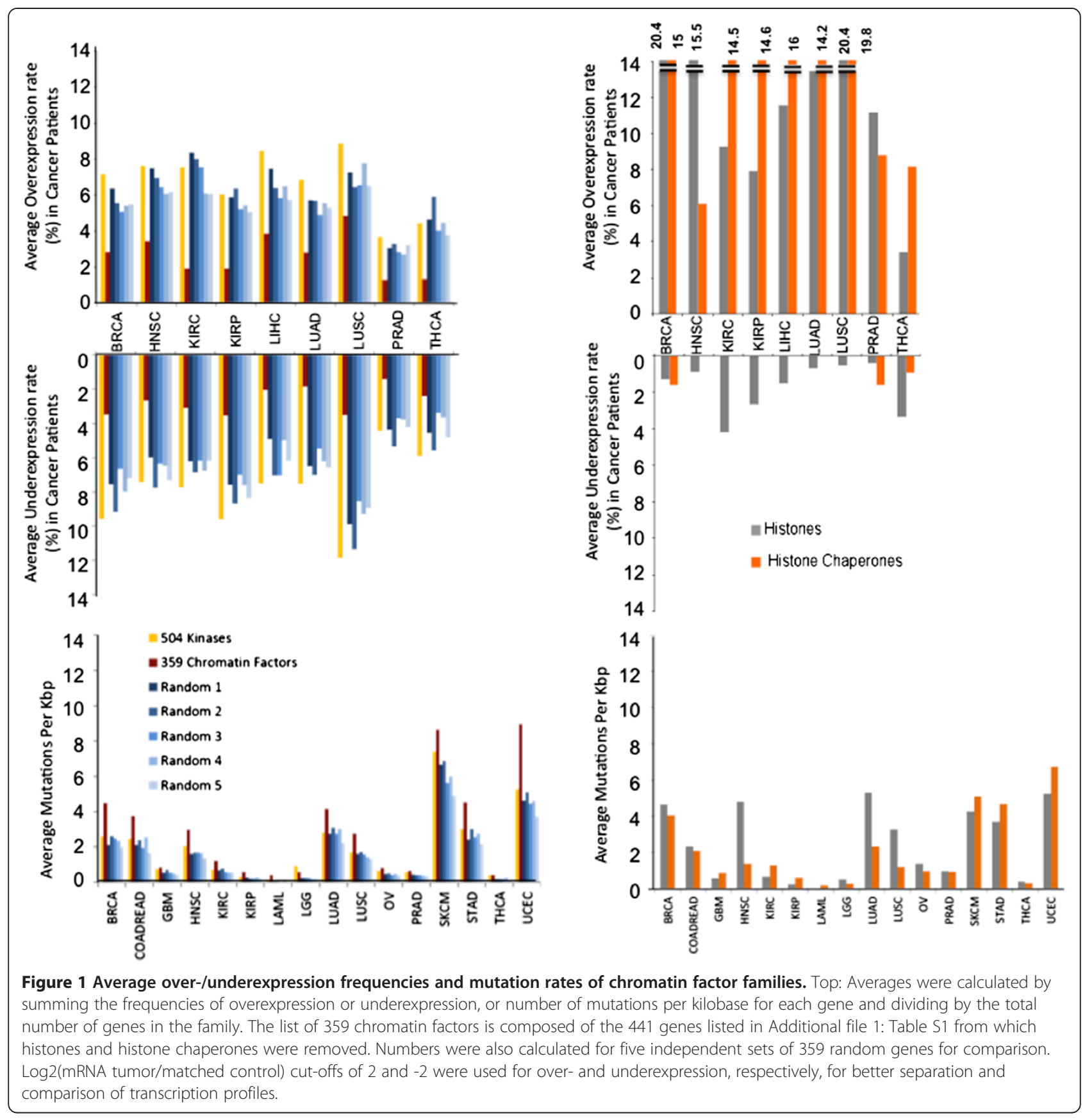

affecting a single chromatin factor may have a strong impact on the expression of a combination of genes involved in cell fate, survival, or DNA damage response.

Finally, we note that histones and their chaperones are dramatically overexpressed in cancer (Figure 1). This probably reflects strong dependence on histones in a highly replicative cellular environment, such as a tumor. The number of histones frequently overexpressed in cancer could also be accentuated by the fact that histones are clustered within restricted genomic areas that may be coregulated. Among enzymes, protein methyltransferases are the most frequently overexpressed across the cancer patient cohorts examined (Additional file 3: Figure S2).

Together, these results show that chromatin factors are more frequently mutated in cancer than random genes, but their expression profile is less variable.

\section{H3K4 and H3K36 methylation are preferentially targeted} by mutations

It has been proposed that site-specific missense mutations that recur across a sizable cohort of cancer patients are indicative of an oncogenic role for the targeted gene, while 
genes that are frequently mutated at random positions are more likely to act as tumor suppressors [25]. A radiometric rule was suggested in which oncogene candidates should be affected at a recurrent position by at least $20 \%$ of missense mutations [25]. Following a similar principle, we searched our 441 chromatin factors for mutation hotspots (Figure 2A,B). As before, this analysis is limited by the depth and breadth of mutational coverage available. For instance, we did not have access to lymphoma data, and failed to retrieve known Y641 mutants that increase the trimethylase activity of EZH2 in this cancer type $[26,27]$. However, acute myeloid leukemia (AML) is covered by our analysis, and we did retrieve the well-known mutation hotspot at position R882 of DNMT3A [21]: 21 of the 54 mutations found on this gene in AML patients map at this position (Figure 2A,B). Similarly, the wellknown mutation hotspot at R132 of IDH1 recurrent in lower grade glioblastoma (LGG) and AML is observed.

We also identified mutation hotspots that, to our knowledge, have not been previously reported (Figure 2A,B). For instance, genes coding for the histone variant H3.1, are mutated in 17 out of 270 head and neck squamous cell carcinoma samples (HNSC), and four of these mutations replace a lysine with methionine at position 36 (twice in HIST1H3C, once in HIST1H3E and once in HIST1H3I) suggesting that $\mathrm{H} 3 \mathrm{~K} 36 \mathrm{M}$ is an oncogenic mutation that drives tumor initiation or progression in a fraction of HNSC patients. Interestingly, an H3K27M mutation is observed in $80 \%$ of diffuse intrinsic pontine gliomas and $22 \%$ of non-brain stem gliomas [28]. The H3K27 methylating PRC2 complex is recruited and trapped by the H3K27M peptide, resulting in an overall decreased methylation of H3K27 at ectopic sites [29]. The authors demonstrated that $\mathrm{H} 3 \mathrm{~K} 36 \mathrm{M}$ and $\mathrm{H} 3 \mathrm{~K} 9 \mathrm{M}$ transgenes also decreased overall amounts of H3K36me2,3 and H3K9me2,3, respectively. This suggests that the H3K36M mutation recurrently observed in HNSC patients may result in reduced levels of methylation at $\mathrm{H} 3 \mathrm{~K} 36$. We also found a H3K36M mutation in a colorectal cancer sample, suggesting that this mechanism may extend to other cancer types. Though statistically significant, we note that the H3K36M mutation rate of $24 \%$ out of the $6.2 \%$ HNSC samples carrying a mutation at $\mathrm{H} 3.1$ remains low. As a comparison, over $40 \%$ of cutaneous melanoma samples carry a mutation in BRAF, $90 \%$ of which are at the hotspot V600E [30].

Another histone, H2B is mutated in seven out of 377 glioblastoma multiform patients, resulting in a G53D mutant in three cases (in HIST1H2BE, HIST1H2BL and HIST1H2BF) (Figure 2A,B). This mutation places an acidic residue in the minor groove of the DNA wrapped around the histone octamer (Additional file 4: Figure S3), which should destabilize nucleosomal $\mathrm{H} 2 \mathrm{~B}$, and possibly nucleosome fluctuation or chromatin architecture.

The PWWP domain is a methyl-lysine reading module that generally binds di- or tri-methylated H3K36. We find that WHSC1, an H3K36 di-methylase that harbors two PWWP domains, is mutated in eight HNSC samples. In

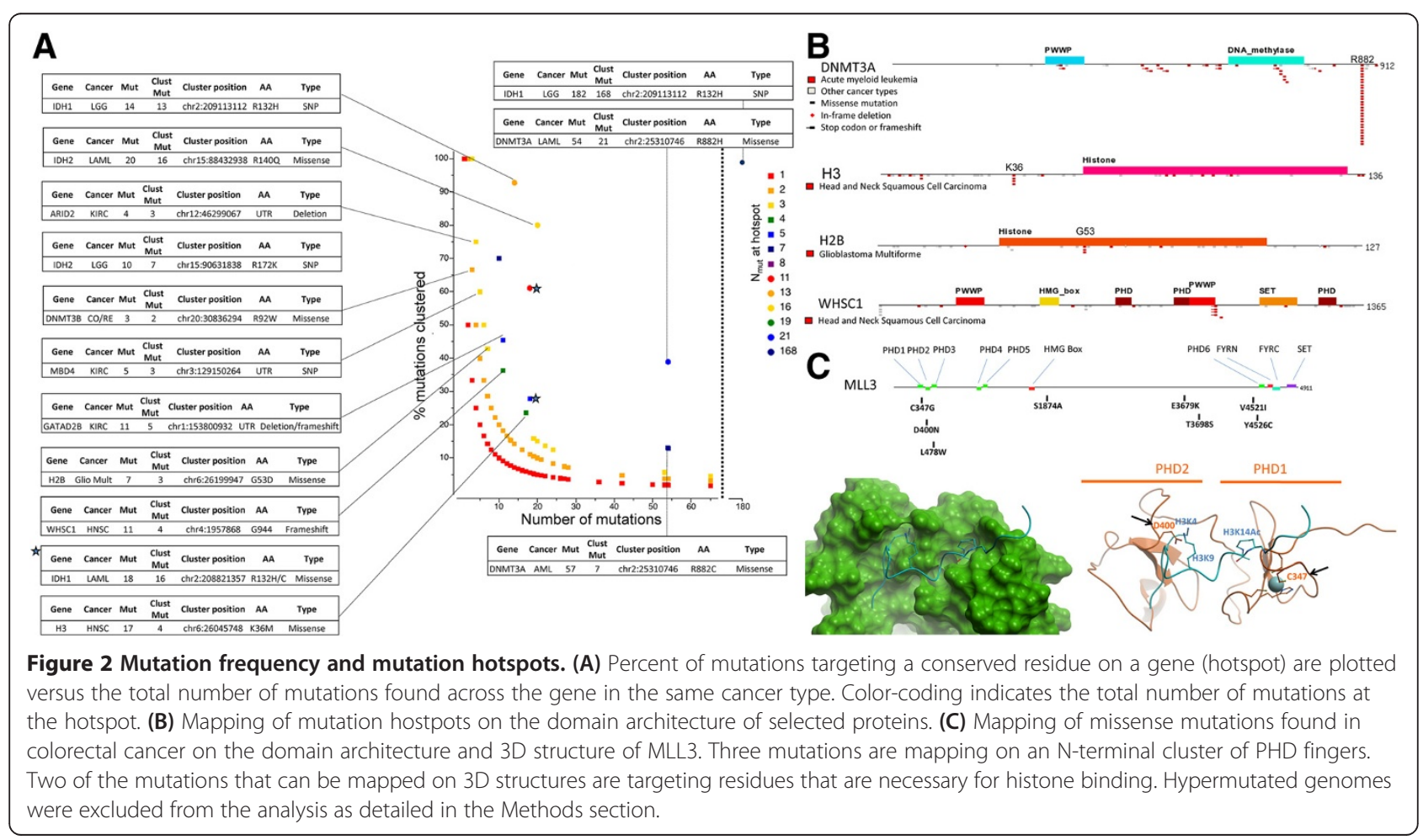


four cases, this produces a frameshift insertion at position G944 of the C-terminal PWWP domain (Figure 2B). This results in deletion of the C-terminal helix of the WHSC1 PWWP domain, expected to cap the methyllysine binding aromatic cage, and may also cause truncation of the methyltransferase domain of WHSC1, located on a downstream exon. In both cases, alteration of H3K36me2 mediated signaling is expected. We find that the H3K36M mutation and WHSC1 frameshifts are mutually exclusive in HNSC tumor samples. Both aberrations are expected to affect H3K36me2 signaling and may represent alternate pathways to the same molecular endpoint.

While mutation hotspots are expected to reveal oncogenes, tumor suppressors are generally targeted by mutations that are more distributed over the gene in cancer. The tumor-suppressor pattern is predominant in chromatin factors (Figure 2A). We find that the H3K36 trimethylase SETD2 and dimethylase NSD1 are among the top 25 most mutated chromatin factors in kidney, head and neck, and lung carcinoma (Table 1). The H3K4 methyltransferases MLL2 and MLL3 are also among the most mutated, with no apparent mutation hotspot, in lung, head and neck, and breast cancers and are therefore tumor suppressor candidates in these tumors. In total, six of the most mutated genes in various cancer types methylate H3K4 or H3K36 (Additional file 2: Figure S1A, Table 1).

Mutations that are not located at a hotspot appear to be more evenly distributed on target genes, but mapping some of these mutations onto protein structures can reveal ingenious residue targeting. For instance, MLL3 missense mutations are found in eight out of 36 colorectal cancer patients from an ICGC study. Mapping these mutations on the domain architecture of the protein shows that three are located on the $\mathrm{N}$-terminal triplePHD finger of the protein (Figure 2C - Top). An apo structure of PHD1,2 of MLL3 was solved (PDB code 2YSM), as well as a structure of the tandem PHD domain of DPF3, a close homolog (40\% sequence identify), in complex with a histone peptide (PDB code $2 \mathrm{KWJ}$ ). Superimposing the two structures allows positioning of the histone peptide relative to the MLL3 PHD fingers. Importantly, we observe that D328 makes critical electrostatic interactions with both $\mathrm{H} 3 \mathrm{~K} 4$ and $\mathrm{H} 3 \mathrm{~K} 9$ in the DPF3 complex, and is conserved in MLL3 (corresponding residue: D400 - Figure 2C - Bottom). Intriguingly, D400N is one of the three mutations affecting the triple PHD finger of MLL3 in colorectal cancer, and, based on these structural observations, should significantly affect histone binding. A second mutation is C347G. This cysteine is one of the four residues coordinating the $\mathrm{Zn}$ atom that holds the first PHD finger together (Figure 2C). The C347G mutation will irremediably affect the structure of this domain, expected to participate in substrate binding.
Somatic mutations affecting MLL3 in colorectal cancer seem therefore to target with high precision residues involved in recruiting the enzyme to appropriately marked loci.

Selective targeting of H3K4 and H3K36 methylation by oncogenic mutations was also observed in other studies that are not yet available from TCGA; for instance, mutations in SETD2 and genes affecting H3K36 methylation are recurrent in high-grade gliomas [31]. Together, these results show that $\mathrm{H} 3 \mathrm{~K} 36$ and $\mathrm{H} 3 \mathrm{~K} 4$ mediated signaling is highly targeted in cancer via hotspot mutations of oncogenes and random mutation of tumor suppressors.

\section{Chromatin factors are involved in a brain tumor-specific gene mutation network}

To identify cancer-associated chromatin factor alterations that are either synergistic or redundant, we searched for co-occurring and mutually exclusive mutation patterns, respectively (Additional file 5: Table S2). Co-occurrence or mutual exclusion with non-chromatin factors was also considered. We find that mutations are co-occurring in ATRX, TP53, and IDH1, and that these are mutually exlusive with mutations in PTEN and EGFR in glioblatoma multiform (GBM) and lower grade glioma (LGG) (Figure 3; Additional file 5: Table S2). For example, TP53 is mutated in $50 \%$ of all LGG samples, but in $95 \%$ of the 80 ATRXmutated samples.

The mutational landscape of adult and pediatric brain cancer has been extensively analyzed (we did not have access to pediatric data in this work) [32,33]. Interestingly, it was found that mutations in IDH1, ATRX, or TP53 were recurrent only in glioma-CpG island methylator phenotype-positive tumors (a phenotype probably attributable to the competitive inhibition of TET demethylases, following accumulation of 2-hydroxyglutarate caused by IDH1 mutation), while mutations in EGFR and PTEN were only observed in other tumor subtypes, which is in agreement with the pattern that we observe [32]. An important mutation that is missed in our exomecentric analysis is an upregulating mutation in the promoter of the telomerase reverse transcriptase (TERT), observed in $58 \%$ to $84 \%$ of primary glioblastomas, suggesting that telomere lengthening plays an important role in tumor growth [34]. Interestingly, ATRX is required for accumulation at telomeres [35], and ATRX mutations promote telomere lengthening and cellular proliferation [36]. Similarly TP53 deficiency favors telomere lengthening [37]. This suggests complementary pressures towards an oncogenic pathway depending on telomere lengthening by mutations co-occurring at ATRX, TP53 and (hypothetically) IDH1 in adult brain tumors where the PTEN/EGFR surface signaling axis is not altered. 


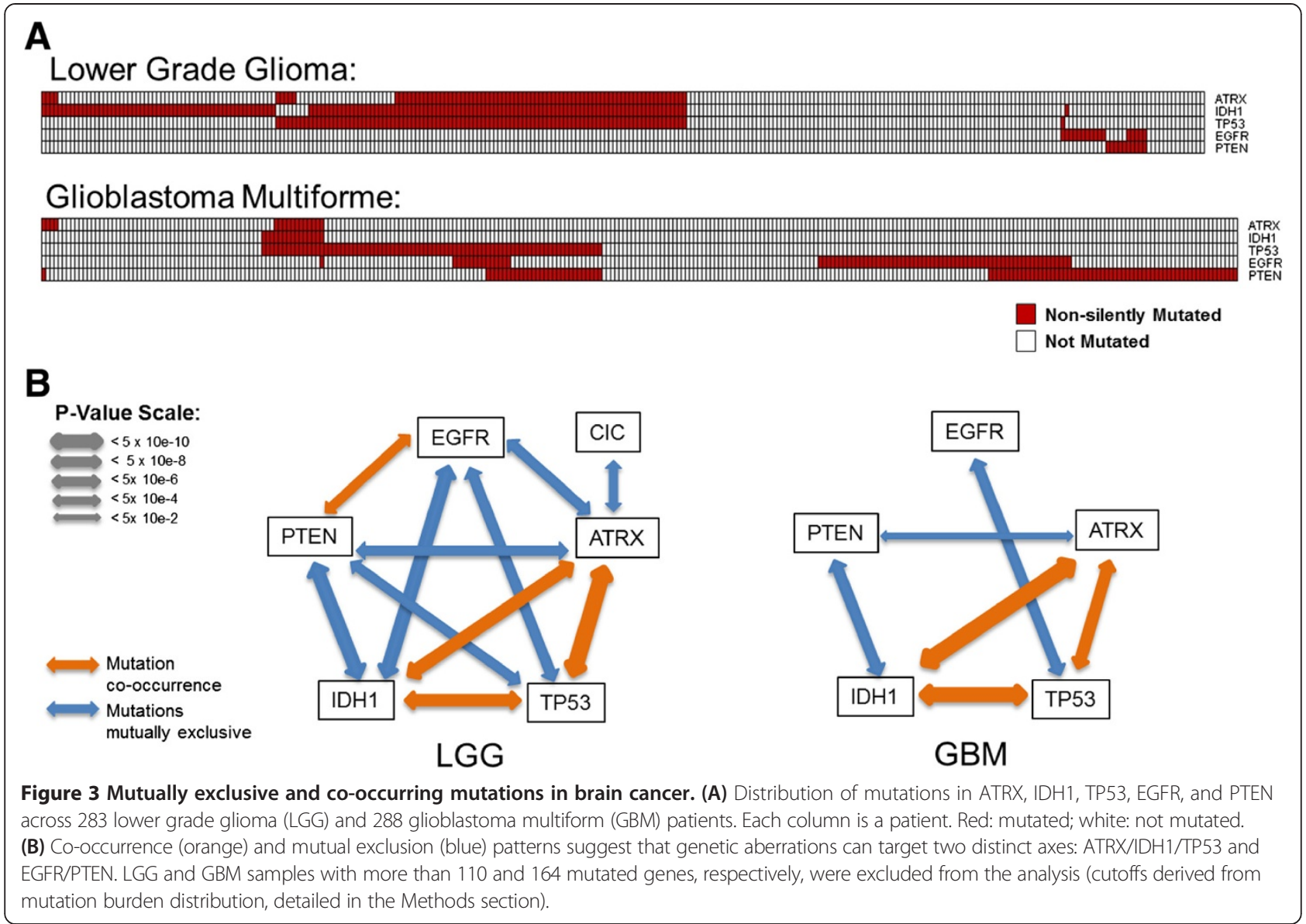

Other intriguing observations include a mutual exclusion in lower grade glioma between ATRX and CIC, a transcriptional repressor that may play a role in development of the central nervous system [38], and mutual exclusion in uterine corpus endometrial carcinoma between mutations at TP53 and SWI/SNF remodeling complex protein ARID1A (Additional file 5: Table S2). This is in agreement with a role in maintenance of DNA integrity for both TP53 and the SWI/SNF complex.

\section{Alteration of chromatin factors involved in replication and genome stability}

We find that some of the changes observed in the cancer epigenome can be associated with a hyperproliferative phenotype, a hallmark of cancer. For instance, histones are twice more frequently overerexpressed than random genes and five to 10 times less frequently underexpressed or mutated in cancer (Figure 1). Additionally, the histone chaperones ASF1B and CHAF1A/B, that are involved in replication-dependent nucleosome assembly [39], are among the most overexpressed histone chaperones, while replication-independent chaperones that maintain nucleosome density and are involved in gene transcription and epigenetic memory, such as DAXX and HIRA [40] are not over-expressed (Figure 4; Additional file 2: Figure S1A,B; Table 1). We also find that the only two proteins known to act as direct links between histone methylation and the DNA replication machinery, ORC1 (that binds to H4K20me3 and recruits the origin of replication complex at replication origins [41]) and UHRF1 (that binds H3K9me3 and recruits DNMT1 to hemi-methylated cytosines [42]), are among the five most frequently overexpressed chromatin factors across all cancer types studied (Additional file 2: Figure S1B).

Another histone chaperone that is significantly overexpressed - actually the most frequently overexpressed chromatin factor in cancer - is HJURP, a chaperone of the histone H3 variant CENP-A, which facilitates aneuploidy and genome instability, another hallmark of cancer [43] (Additional file 2: Figure S1B; Table 1). Expression level of HJURP was previously reported to correlate with glioblastoma cell survival, and was found to be a predictive biomarker for sensitivity to radiotherapy in breast cancer $[44,45]$.

The DNA repair machinery is an important factor in genome instability, and we find that it is repeatedly 


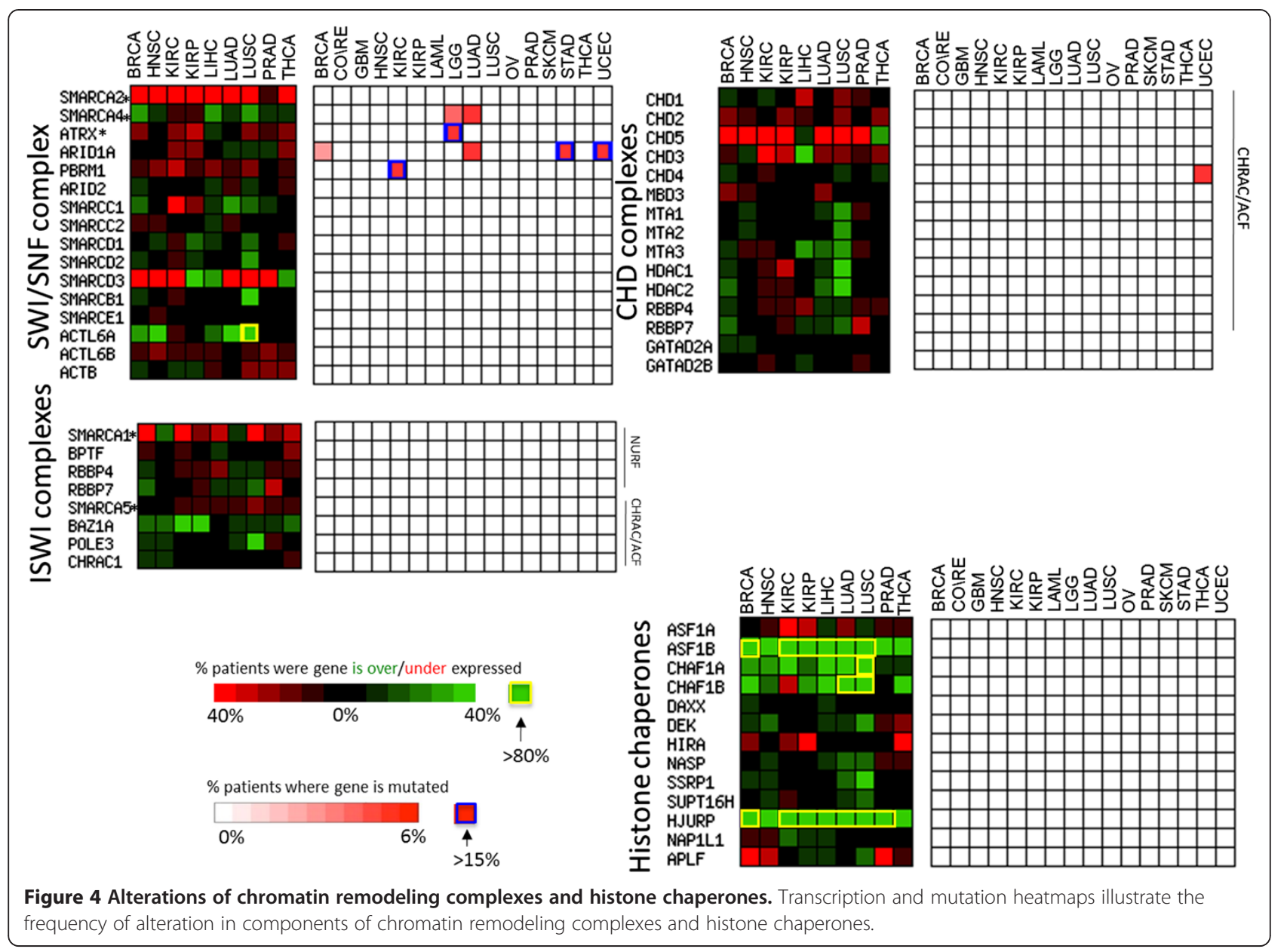

targeted through alteration of epigenetic mechanisms in cancer. SETD2 is among the most mutated chromatin factors in kidney renal clear cell and lung adeno carcinomas (Table 1). SETD2 trimethylates H3K36, a mark that regulates DNA mismatch repair through recruitment of the PWWP domain of MSH6 [46]. Additionally, SETD2 was recently shown to act as a guardian of transcriptome integrity by preventing intragenic transcription initiation [47]. The PMT SETMAR includes both methyltransferase and transposase domains, and both domains are essential for double-strand break repair [48]. We find that SETMAR is recurrently underexpressed in tumor samples, including in $54 \%$ of HNSC and $78 \%$ of kidney renal clear cell carcinoma patients (Additional file 2: Figure S1). ATRX, ARID1A, PBRM1, and SMARCA4 are also among the most frequently mutated chromatin factors in cancer (Table 1; Figure 4), and are all components of the chromatin remodeling complex SWI/SNF, which has been shown to facilitate double-strand break repair [49]. Additionally, ATRX is responsible for the incorporation H3.3 at telomeres, and its mutation can cause alternative telomere lengthening, associated with increased genomic instability [20].
These observations strongly suggest that genetic or transcriptional aberrations targeting chromatin factors in cancer favor replication and contribute to genome instability. We note a potential synergy between these targeted events and other mechanisms that also link epigenetic mechanisms to alteration of DNA maintenance in cancer. These include hypermethylation at DNA promoter regions of genes involved in DNA repair, or direct control of regional mutation rates through chromatin organization $[1,50]$.

\section{Gene amplification rarely drive transcriptional alterations} of chromatin factors

Cancer genomes generally have large numbers of 'passenger' mutations and a small number of driver genetic events. Additionally, cancer-associated overexpression does not necessarily imply disease-relevance. However, when overexpression is caused by a chromosomal aberration, disease-relevance is more likely [51,52]. To identify candidate drivers affecting epigenetic mechanisms, we looked for correlations between copy number gains and overexpression of chromatin factors in cancer samples compared with matched normal samples [51,52]. 
We find that in the vast majority of cases, overexpression is not correlated with copy number gain. For instance, EZH2 and UHRF1 are two of the most frequently overexpressed chromatin factors but are rarely amplified in cancer (Figure 5A,B). This comes as no surprise, since multiple factors can affect the transcriptional levels of a gene, such as DNA methylation of promoter or enhancer elements, expression levels of ncRNA, transcription factors or chromatin factors controlling expression of this gene. Nevertheless, we do find that gene overexpression correlates remarkably with gene amplification in a few cases. Clear correlation is observed for the H3K9 trimethylase SETDB1, significantly amplified and overexpressed in $16 \%$ of lung adenocarcinoma samples (Figure 5C). Amplification of the SETDB1 gene in lung cancer was recently shown to contribute to lung tumorigenesis, and shRNAmediated depletion of SETDB1 in amplified cells reduced tumor growth in a mouse xenograft model [53]. Another example is the H3K36 dimethylase WHSC1L1/NSD3 amplified and overexpressed in $18 \%$ and $8 \%$ of lung squamous cell and breast invasive carcinomas, respectively (Figure 5D). WHSC1L1 is in the 8p11.2-p12 amplicon, previously reported in $10 \%$ to $15 \%$ breast cancers, and associated with poor prognosis [54]. This amplicon includes other genes that may also act as oncogenes, such as FGFR1. Interestingly, knockdown of WHSC1L1 results in profound loss of growth survival of 8p11-12 amplified breast cancer cells, but not control MCF10A cells [55]. These results suggest that amplification of WHSC1L1 drives cancer in a subset of breast cancer patients.
WHSCI1L1 overexpression is even more frequent in lung squamous cell carcinoma and its amplification may also be a driving event in a subset of patients. Among our 441 chromatin factors, the most frequently amplified/overexpressed genes were ACTL6A, a component of the SWI/ SNF chromatin remodeling complex that is overexpressed and amplified in 53\% of lung squamous cell carcinoma samples, and $F X R 1$, a gene that codes for a Tudor domain containing protein that is also overexpressed and amplified in $53 \%$ of the same tumor type. In both cases, expression levels correlate strongly with copy number gains (Figure 5E,F). Both genes are actually located at the 3q2629 amplicon, which is prevalent in lung squamous cell carcinoma [56]. Integrative genomic analysis pointed at genes involved in ubiquitylation pathway as candidate drivers, while microarray expression profiles indicated that FXR1 was one of three genes from the amplicon consistently overexpressed in lung squamous cell carcinoma $[57,58]$. Of the close to 250 genes located at the 3q26-29 amplicon, we find that ACTL6A and FXR1 are among the 10 and 30 most frequently overexpressed genes in this cancer type, respectively. Vulnerability of cancer cells to ACTL6A or FXR1 knock-out would be necessary to characterize the role of these genes in lung squamous cell carcinoma.

Together, these results show that overall copy number variation do not appear to drive transcriptional deregulation of most chromatin factors and are therefore likely to be passenger events in cancer. Nevertheless, in rare cases, recurrent gene amplifications do appear to
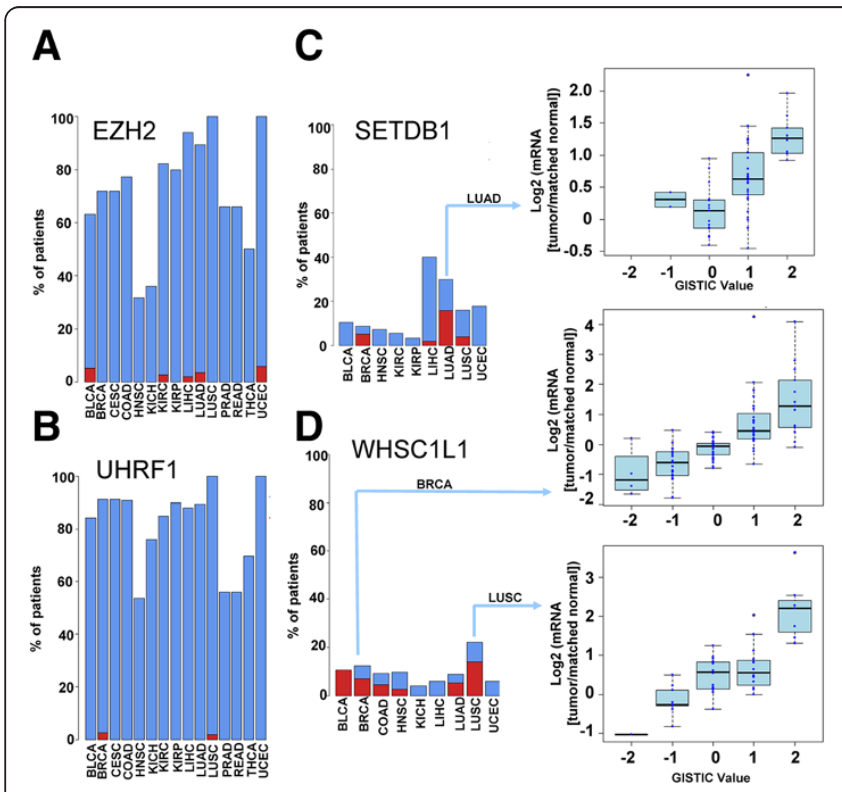

Figure $\mathbf{5}$ Correlation between mRNA expression and copy number variation. (A-F) Recurrence of gene overexpression in tumor samples across different cancer types (blue bars - log2(mRNA(tumor/matched normal)) >1) compared with recurrence of gene amplification (red bars GISTIC $=2$ and log2(mRNA(tumor/matched normal)) >1). (C-F) Box plots distribution of changes in gene expression levels (log2(mRNA(tumor/matched normal))) in tumor samples grouped by GISTIC values (that is, levels of copy number variation).

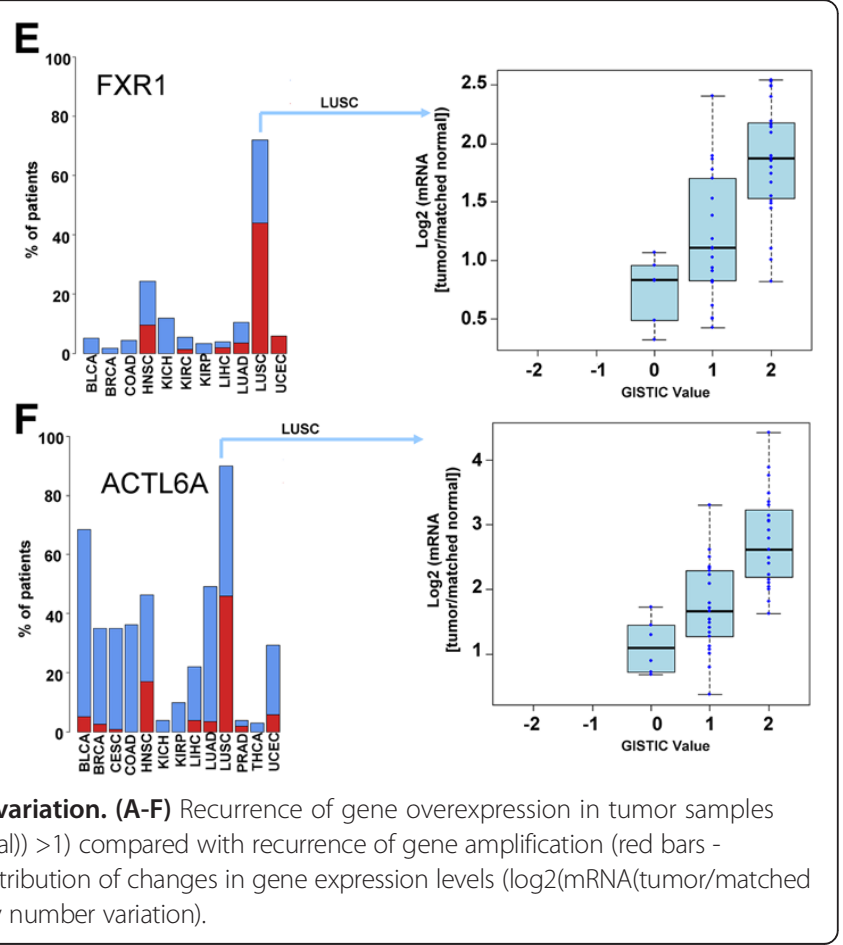


drive overexpression of a given chromatin factor in tumor samples. Genetic or pharmacologic targeting of these genes will be necessary to further investigate their role in tumor initiation and progression.

\section{Discussion}

Recent landmark next-generation sequencing campaigns of large cancer patient cohorts repeatedly revealed recurrent alterations of genes involved in epigenetic mechanisms [20,23,24,59-61]. The data associated with most of these and other unbiased cancer genomic projects were deposited in TCGA and the ICGC repositories, and made publicly accessible to the scientific community $[14,16]$. Here, we took a systematic approach to analyze this aggregated data across a list of 441 genes involved in chromatinmediated signaling.

Specific combinations of post-translational modifications of DNA and histones at distinct genomic elements control chromatin compaction, nucleosome occupancy, and gene activation status [62]: histone acetylation and H3K4 di- or tri-methylation at promoters, H3K4 monomethylation at enhancers and tri-methylation of $\mathrm{H} 3 \mathrm{~K} 36$ as well as DNA methylation in gene bodies are associated with transcriptionally active genes. Promoters trimethylated at H3K4 and H3K27 are thought to be in a state that is transcriptionally repressed, but 'poised' for rapid activation upon demethylation of H3K37. Finally, tri-methylated H3K9 and methylated DNA at enhancers, or a combination of these two marks with trimethylated
H3K27 at promoters, is associated with gene silencing (Figure 6A,B).

Intriguingly, we find that enzymes that deposit histone marks associated with gene activation, such as the H3K4 trimethylases MLL1-4 and SETD1A/B, or the H3K36 trimethylase SETD2 are more often repressed and mutated in cancer (Figure 6C). On the other hand, enzymes that deposit repressive histone marks, such as the H3K9 trimethylases SETDB1 or SUV39H1/2, and the H3K27 trimethylase EZH2 are overexpressed in most cancer types studied. The trend is not as clear for demethylase, but we note that KDM5B, which removes the activating mark H3K4me3, is significantly overexpressed in five of the eight cancer types studied and never repressed, while the H3K27me3 demethylases KDM6A/B are repressed in most cancer types (Figure $6 \mathrm{C}$ ). Alterations in genes regulating histone methylation appear therefore to be biased towards silencing histone marks. The functional relevance of this observation is unclear. We note that alterations of genes regulating DNA methylation do not follow a similar trend (Figure 6C), and that transcription levels are not repressed in tumor samples when averaging across the whole genome (Additional file 6: Figure S4). In this regard, it is unlikely that a general trend in the control of transcription applies across all tumors, considering the divergence in molecular mechanisms driving different cancer subtypes.

Currently approved epigenetic drugs are DNMT and HDAC inhibitors against myelodysplastic syndrome, acute myeloid leukemia, and lymphoma. With the exceptions of

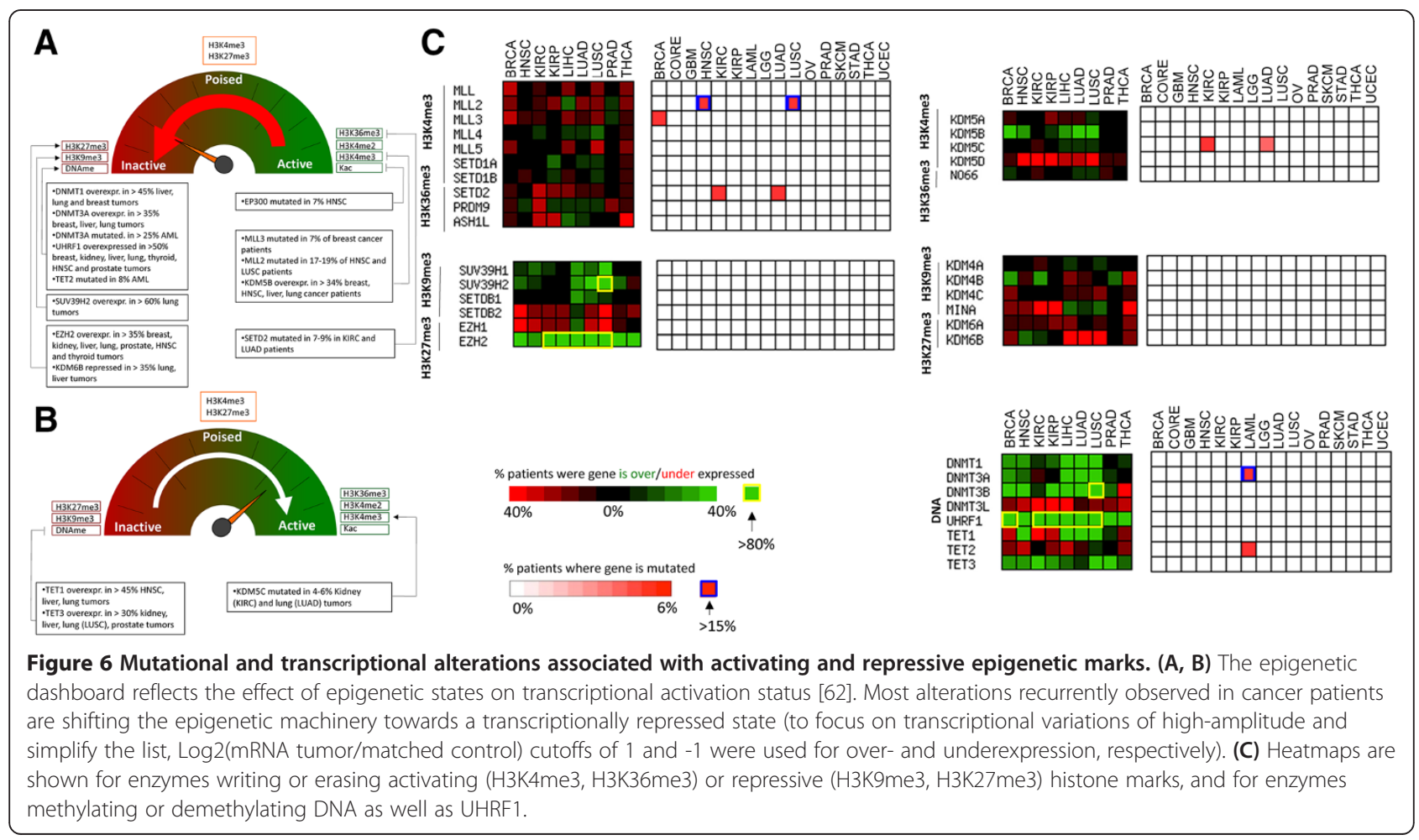


DNMT3B, which is significantly overexpressed in most cancer types studied here, and DNMT3A which is highly mutated in LAML, we do not see notable mutation rates or cancer-associated changes in expression level for DNMTs and HDACs (Additional file 2: Figure S1). We also note that the mode of action of these first generation drugs remains unclear and their toxicity profile mediocre. Some of the emerging epigenetic drugs, such as bromodomain, protein methyltransferase, or IDH1 inhibitors, are targeting patient group with clear oncogenic chromosomal aberrations such as gene fusions at BRD4 and MLL1, or mutations at IDH1 [6,63,64]. Translocations are not included in our analysis, but IDH1 mutations are high on our chromatin factor mutation landscape (Additional file 2: Figure $\mathrm{S} 1 \mathrm{~A})$. Other peaks, such as ATRX mutations in lower grade glioma or ARID1A mutations in endometrial cancer and stomach adenocarcinoma may represent other points of entry for therapeutic intervention.

\section{Conclusions}

The refined complexity of chromatin as a signaling platform, and its dysregulation in cancer, can only be dissected through systematic identification and functional characterization of all chromatin factors, in specific tissue types, and at specific stages of cancer progression. Here, we apply a reductionist approach to identify general trends associated with protein families or chromatin complexes that are primary determinants of the cancer epigenome. This analysis is restricted by the limited but rapidly growing number of cancer types that are represented at TCGA and the ICGC repositories. It is also limited by restrictions that we imposed to focus on statistically significant patient cohorts and on non-hypermutated genomes (see Methods section for details). It has been proposed that most epigenetic-associated mutations are observed in hematological, in pediatric, or in rare and aggressive variants of solid tumors [9]. It was also noted that, contrary to the general pattern identified here, H3K4me3 and H3K36me3 marks are upregulated during epithelial to mesenchymal transition, an important step in cancer progression [9]. As the volume of cancer genomics data grows, future analysis similar to the one presented here should capture with more accuracy epigenetic transformations underlying distinct types and stages of cancer.

\section{Methods}

\section{Data access}

All raw data analyzed can be accessed and downloaded via the Broad TCGA GDAC Firehose (http://gdac.broad institute.org/) or the ICGC data portal (http://dcc.icgc.org/). Somatic mutation, copy number variation, RNASeq gene expression, and DNA methylation data downloaded via TCGA's Firehose was extracted from the 'stddata Run' and is pre-processed. This means the data have been mapped to genes, genomic locations, and a variety of auxiliary data has been added (ex. Amino acid change for mutation data). This type of pre-processed data is referred to as 'Level 3' data using TCGA's nomenclature. Only pre-processed somatic mutation data (version 12) referred to as 'Simple Mutation' were downloaded from the ICGC data portal. Further analyzed data, known as Level 4', are extracted for somatic mutation and copy number data from the analyses run'. Level 4 data are produced by taking level 3 data and running an algorithm that further isolates statistically significant alterations. For mutation data the algorithm used is MutSigCV [65], while GISTIC 2.0 [66] is used for copy number data.

\section{Cancer types}

In most cases, nomenclature and abbreviations of cancer types used at TCGA and the ICGC were preserved. These are TCGA: BRCA: invasive breast carcinoma, COAD: colon adenocarcinoma, COADREAD: colon and rectum adenocarcinoma, GBM: glioblastoma multiforme, LUAD: lung adenocarcionma, LAML: acute myeloid leukemia, HNSC: head and neck squamous cell carcinoma, KIRC: kidney renal clear cell carcinoma, KIRP: kidney renal papillary cell carcinoma, LGG: lower grade glioma, LUSC: lung squamous cell carcinoma, OV: ovarian serous cystadenocarcinoma, SKCM: skin cutaneous melanoma, STAD: stomach adenocarcinoma, THCA: thyroid carcinoma, LIHC: liver hepatocellular carcinoma, PRAD: prostate adenocarcinoma, and UCEC: uterine corpus endometrioid carcinoma (The Cancer Genome Atlas Network). For ICGC: breast carcinoma, breast cancer, colorectal cancer, glioblastoma multiforme, lung adenocarcinoma, myeloproliferative disorders, chronic lymphocytic leukemia, liver cancer, pediatric brain tumors, and pancreatic cancer. Mutation data downloaded from the TCGA were excluded from the ICGC downloads. In a few cases, distinct patient cohorts from TCGA and the ICGC were affected by similar cancer types. These were merged as follows: breast cancer, breast carcinoma cohorts from ICGC and BRCA cohort from TCGA, colorectal cancer, COADREAD and READ cohorts from TCGA, glioblastoma multiforme cohort from ICGC and GBM cohort from TCGA, lung adenocarcinoma cohort from ICGC and LUAD cohort from TCGA.

\section{Somatic mutations}

Somatic mutations relative to the reference human genome (hg18 for COAD/READ, LAML and OV; hg19 for all other cancer types) are extracted from sequencing data using complex algorithms (which are not discussed here since this pre-processing step is conducted at TCGA and the ICGC) and linked to anonymized patient ID, affected gene/transcript, chromosomal position, and nucleotide/amino acid change. For each patient, the overall number of genes mutated within the tumor sample 
genome is stored and used to filter out cancer genomes with unusually high number of mutations. This cutoff differs across cancer types based on their mutation level. In order to determine this cutoff, for each cancer type cohort analyzed, the number of mutated genes was plotted across all patients and a value equivalent to the mean $+3 *$ standard deviation of the normal distribution was used to set the cutoff (Additional file 7: Figure S5). Any tumor with more mutated genes than the cutoff set for that cancer type was excluded from the analysis when analyzing mutations hotspots and mutation co-occurrence/ mutual exclusion, that is, when comparing each individual patient. In other analyses, where the readout is the frequency of mutation, we rely on MutSigCV, which accounts for background mutation rates, gene length, and other source of noise (q value $\leq 0.1$ ) [65]. No normal distribution, but a continuum of highly mutated genomes were found for lung squamous cell carcinoma and skin cutaneous melanoma, and these two patient cohorts were therefore excluded from our recurrent mutation analysis. Since the frequency of mutation of a single gene is low, cohorts that were less than 100 patients were excluded. Additionally, mutation frequencies that were derived from less than three mutations, and mutations at poly-Q regions were excluded from further analysis to reduce noise levels. The mutation frequencies that we observed for our 1,000 random genes across diverse cancer types differs from that previously published [25]. We attribute this apparent discrepancy due to the fact that level 3 mutation data that we obtain from TCGA and the ICGC are pre-processed to eliminate false-positives. This is in agreement with previous work showing that some cancer types are particularly enriched in false mutation calling. For instance, preprocessing can reduce the number of frequently mutated genes in lung cancer from 450 to 11 [65].

\section{Co-mutation analysis}

Using $2 \times 2$ contingency tables we produced fisher $P$ values, odds ratios, and $95 \%$ confidence intervals for each possible pairing of genes present in Additional file 1: Table S1. Two-sided Fisher's exact test was used to produce $P$ values and only those that were $\leq 0.05$ were considered significant. Odds ratios and confidence intervals were produced as previously reported [67]. Odds ratios $>1$ were considered to imply mutation co-occurrence, while odds ratios $<1$ implied mutation mutual exclusion. Gene pairs with a confidence interval containing 0 was considered statistically insignificant.

\section{mRNA expression}

TCGA level 3 RNASeq gene expression data were downloaded from the Broad Institute's Firehose (RNASeq V2 data). Only data from patients with matched tumor and normal samples were used. Cancer types with cohorts under 30 patients were excluded. This threshold is more permissive than the 100 patient cohort used for somatic mutations, as frequencies of transcriptional changes in tumor samples are typically an order of magnitude higher than mutation frequencies. RSEM values are used to quantify mRNA expression levels [68]. A log2 fold change in gene expression is calculated from RSEM values of tumor and matched normal samples as follows:

$$
\begin{aligned}
\log 2 \text { fold change }= & \log 2(\operatorname{RSEM}[\text { tumor }] \\
& \div \operatorname{RSEM}[\text { matched normal }])
\end{aligned}
$$

Frequencies were calculated for each gene and cancer type as the percentage of patients with a log2 fold change greater than 1 for overexpression or lower than -1 for underexpression.

\section{Average frequencies in over-/underexpression and mutation across protein families}

Average frequencies in over-/underexpression and mutation across protein families (Figure 1) were generated for each cancer type by summing frequencies shown in Figure 1 (after changing the Log2 cutoff from 1 to 2 to focus on transcriptional changes of higher amplitude) and dividing by the total number of genes present within the indicated protein family.

\section{Copy number variation}

GISTIC values are used to evaluate copy number variations relative to the reference genome (hg18 for COAD/READ, LAML and OV; hg19 for all other cancer types) [66]. GISTIC values of 1 and 2 indicate moderate and high copy number gains, respectively, while values of -1 and -2 indicate hetero- and homozygous deletions, respectively. All GISTIC copy number data are directly downloaded from TCGA's Firehose interface (level 4 data). Anonymous patient ID provided by TCGA was used to determine patients where both GISTIC copy number and matched-control RNASeq gene expression data were available. Corresponding patient cohorts with fewer than 15 patients were excluded. These data were used to find correlations between copy number variation and gene expression levels in tumor samples. For interested readers, we made correlations for all cancer types available on the Chromohub website [69].

\section{Identification of mutation hotspots}

Mutation hotspots were defined as aminoacids affected by a minimum of three mutations representing at least $20 \%$ of non-silent mutations for that gene in a given cancer type. Highly mutated genomes were ignored, as previously specified. 


\section{Additional files}

Additional file 1: Table S1. Four hundred and forty-one chromatin factors used in this study and their respective association with epigenetic protein families.

Additional file 2: Figure S1. Mutation and transcription heatmaps of chromatin factors. Color codes illustrate the frequency of cancer patients where (A) a gene is mutated (non-silent mutations only), (B) where Log2 (mRNA tumor/matched control) $>1$ for overexpression, and $(\mathbf{C})$ where Log2(mRNA tumor/matched control) <-1 for underexpression. All data were extracted from TCGA and the ICGC. (D) Color codes indicate how a gene ranks in the genome based on the frequency with which it is over-/underexpressed in cancer. Patient cohorts are greater than 30 for overexpression and 100 for mutations. Hypermutated genomes and other sources of noise were excluded (detailed in the Methods section).

Additional file 3: Figure S2. Average over-/underexpression frequencies and mutation rates of chromatin factor families. Averages were calculated as in Figure 1.

Additional file 4: Figure S3. Mapping of the H2B G53D mutation on the nucleosome structure. An aspartate was modeled at position 53 of H2B in the structure of the human nucleosome (PDB code 3AFA). The histone octamer is shown as ribbons ( $\mathrm{H} 2 \mathrm{~B}$ is in cyan). DNA is shown as a mesh colored according to its electrostatic potential (red: electronegative).

Additional file 5: Table S2. Co-occurring and mutually exclusive mutations. First tab: all genes. Second tab: focused on ATRX, IDH1, TP53, PTEN, and EGFR in LGG and GBM.

Additional file 6: Figure S4. Overall change in expression in tumor samples presenting a genetic or transcriptional aberration affecting a specific chromatin factor. Patient cohorts are groups within box plots where log2(gene expression tumor/matched control) is averaged across the human genome. Cohort sizes for each boxplot are indicated in parenthesis. Light blue: indicated chromatin factor is repressed in tumor samples $(\log 2<-1)$. Red: indicated chromatin factor is mutated in tumor samples.

Additional file 7: Figure S5. Exclusion of hypermutated genomes was derived for each cancer type from the distribution of the number of mutated genes per cancer patients. The normal distribution section of the curve was used to calculate a cutoff (indicated with a red vertical bar) as the mean of the normal distribution +3 standard deviations. Genomes with more genes mutated than this cutoff were excluded throughout this work. The resulting cutoffs and size of patient cohorts are indicated in the summary table.

\section{Competing interests}

The authors declare that they have no competing interests.

\section{Authors' contributions}

MAS and ELD conducted the computational and statistical work. CHA and $\mathrm{ML}$ analyzed the data and provided constructive comments. MS designed the work, analyzed the data and wrote the manuscript. All authors read and approved the final manuscript.

\section{Acknowledgements}

The SGC is a registered charity (number 1097737) that receives funds from AbbVie, Bayer, Boehringer Ingelheim, Canada Foundation for Innovation, Genome Canada through the Ontario Genomics Institute (OGI-055), GlaxoSmithKline, Janssen, Lilly Canada, the Novartis Research Foundation, the Ontario Ministry of Economic Development and Innovation, Pfizer, Takeda, and the Wellcome Trust (092809/Z/10/Z)

\section{Author details}

'Structural Genomics Consortium, University of Toronto, MaRS Centre, South Tower, 101 College Street, Toronto M5G 1L7, ON, Canada. ${ }^{2}$ Princess Margaret Cancer Centre and Department of Medical Biophysics, University of Toronto, Toronto M5G 2M9, ON, Canada. ${ }^{3}$ Department of Pharmacology and Toxicology, University of Toronto, 1 King's College Circle, Toronto M5S 1A8, ON, Canada. ${ }^{4}$ Current address: Courant Institute, New York University, 12 th floor, 715 Broadway, New York 10003, USA.
Received: 12 August 2014 Accepted: 14 October 2014

Published: 4 December 2014

\section{References}

1. Baylin SB, Jones PA: A decade of exploring the cancer epigenome biological and translational implications. Nat Rev Cancer 2011, 11:726-734.

2. You JS, Jones PA: Cancer genetics and epigenetics: two sides of the same coin? Cancer Cell 2012, 22:9-20.

3. Marks PA, Breslow R: Dimethyl sulfoxide to vorinostat: development of this histone deacetylase inhibitor as an anticancer drug. Nat Biotechnol 2007, 25:84-90.

4. Kaminskas E, Farrell AT, Wang YC, Sridhara R, Pazdur R: FDA drug approval summary: azacitidine (5-azacytidine, Vidaza) for injectable suspension. Oncologist 2005, 10:176-182.

5. Copeland RA: Molecular pathways: protein methyltransferases in cancer. Clin Cancer Res 2013, 19:6344-6350.

6. Filippakopoulos P, Knapp S: Targeting bromodomains: epigenetic readers of lysine acetylation. Nat Rev Drug Discov 2014, 13:337-356.

7. Ryan RJ, Bernstein BE: Molecular biology. genetic events that shape the cancer epigenome. Science 2012, 336:1513-1514.

8. Shen H, Laird PW: Interplay between the cancer genome and epigenome. Cell 2013, 153:38-55.

9. Timp W, Feinberg AP: Cancer as a dysregulated epigenome allowing cellular growth advantage at the expense of the host. Nat Rev Cancer 2013, 13:497-510.

10. Workman P, Al-Lazikani B: Drugging cancer genomes. Nat Rev Drug Discov 2013, 12:889-890.

11. Plass C, Pfister SM, Lindroth AM, Bogatyrova O, Claus R, Lichter P: Mutations in regulators of the epigenome and their connections to global chromatin patterns in cancer. Nat Rev Genet 2013, 14:765-780.

12. Ciriello G, Miller ML, Aksoy BA, Senbabaoglu Y, Schultz N, Sander C: Emerging landscape of oncogenic signatures across human cancers. Nat Genet 2013, 45:1127-1133.

13. Kandoth C, McLellan MD, Vandin F, Ye K, Niu B, Lu C, Xie M, Zhang Q McMichael JF, Wyczalkowski MA, Leiserson MD, Miller CA, Welch JS, Walter MJ, Wendl MC, Ley TJ, Wilson RK, Raphael BD, Ding L: Mutational landscape and significance across 12 major cancer types. Nature 2013, 502:333-339.

14. Cancer Genome Atlas Research Network, Weinstein JN, Collisson EA, Mills GB, Shaw KR, Ozenberger BA, Ellrott K, Shmulevich I, Sander C, Stuart JM: The cancer genome atlas pan-cancer analysis project. Nat Genet 2013, 45:1113-1120.

15. Garraway LA, Lander ES: Lessons from the cancer genome. Cell 2013, 153:17-37.

16. International Cancer Genome Consortium, Hudson TJ, Anderson W, Artez A, Barker AD, Bell C, Bernabe RR, Bhan MK, Calvo F, Eerola I, Gerhard DS, Guttmacher A, Guyer M, Hemsley FM, Jennings JL, Kerr D, Klatt P, Kolar P, Kusada J, Lane DP, Laplace F, Youyong L, Nettekoven G, Ozenberger B, Peterson J, Rao TS, Remacle J, Schafer AJ, Shibata T, Stratton MR, et al: International network of cancer genome projects. Nature 2010, 464:993-998.

17. Clapier CR, Cairns BR: The biology of chromatin remodeling complexes. Annu Rev Biochem 2009, 78:273-304.

18. Lu C, Ward PS, Kapoor GS, Rohle D, Turcan S, Abdel-Wahab O, Edwards CR, Khanin R, Figueroa ME, Melnick A, Wellen KE, O'Rourke DM, Berger SL, Chan T, Levine RL, Mellinghoff IK, Thompson CB: IDH mutation impairs histone demethylation and results in a block to cell differentiation. Nature 2012, 483:474-478.

19. Chase A, Cross NC: Aberrations of EZH2 in cancer. Clin Cancer Res 2011 $17: 2613-2618$.

20. Schwartzentruber J, Korshunov A, Liu XY, Jones DT, Pfaff E, Jacob K, Sturm D, Fontebasso AM, Quang DA, Tonjes M, Hovestadt V, Albrecht S, Kool M, Nantel A, Konermann C, Lindroth A, Jager N, Rausch T, Ryzhova M, Korbel JO, Hielscher T, Hauser P, Garami M, Klekner A, Bognar L, Ebinger M, Schuhmann MU, Scheurlen W, Pekrun A, Fruhwald MC, et al: Driver mutations in histone $\mathrm{H} 3.3$ and chromatin remodelling genes in paediatric glioblastoma. Nature 2012, 482:226-231.

21. Ley TJ, Ding L, Walter MJ, McLellan MD, Lamprecht T, Larson DE, Kandoth C, Payton JE, Baty J, Welch J, Harris CC, Lichti CF, Townsend RR, Fulton RS, Dooling DJ, Kobolt DC, Schmidt H, Zhang Q, Osborne JR, Lin L, O'Laughlin M, 
McMichael JF, Delehaunty KD, McGrath SD, Fulton LA, Magrini VJ, Vickery TL, Hundal J, Cook LL, Conyers JJ, et al: DNMT3A mutations in acute myeloid leukemia. N Engl J Med 2010, 363:2424-2433.

22. Weissmann S, Alpermann T, Grossmann V, Kowarsch A, Nadarajah N, Eder C, Dicker F, Fasan A, Haferlach C, Haferlach T, Kern W, Schnittger S, Kohlmann A: Landscape of TET2 mutations in acute myeloid leukemia. Leukemia 2012, 26:934-942.

23. Ellis MJ, Ding L, Shen D, Luo J, Suman VJ, Wallis JW, Van Tine BA, Hoog J, Goiffon RJ, Goldstein TC, Ng S, Lin L, Crowder R, Snider J, Ballman K, Weber J, Chen K, Koboldt DC, Kandoth C, Schierding WS, McMichael JF, Miller CA, Lu C, Harris CC, McLellan MD, Wendl MC, DeSchnyver K, Allred DC, Esserman L, Unzeitig $G$, et al: Whole-genome analysis informs breast cancer response to aromatase inhibition. Nature 2012, 486:353-360.

24. Varela I, Tarpey P, Raine K, Huang D, Ong CK, Stephens P, Davies H, Jones D, Lin ML, Teague J, Bignell G, Butler A, Cho J, Dalgliesh GL, Galappaththige D, Greenman C, Hardy C, Jia M, Latimer C, Lau KW, Marshall J, McLaren S, Menzies A, Mudie L, Stebbings L, Largaespada DA, Wessels LF, Richard S, Kahnoski RJ, Anema J, et al: Exome sequencing identifies frequent mutation of the SWI/SNF complex gene PBRM1 in renal carcinoma. Nature 2011, 469:539-542.

25. Vogelstein B, Papadopoulos N, Velculescu VE, Zhou S, Diaz LA Jr, Kinzler KW: Cancer genome landscapes. Science 2013, 339:1546-1558.

26. Yap DB, Chu J, Berg T, Schapira M, Cheng SW, Moradian A, Morin RD, Mungall AJ, Meissner B, Boyle M, Marquez VE, Marra MA, Gascoyne RD, Humphries RK, Arrowsmith CH, Morin GB, Aparicio SA: Somatic mutations at EZH2 Y641 act dominantly through a mechanism of selectively altered PRC2 catalytic activity, to increase H3K27 trimethylation. Blood 2011, 117:2451-2459.

27. Sneeringer CJ, Scott MP, Kuntz KW, Knutson SK, Pollock RM, Richon VM, Copeland RA: Coordinated activities of wild-type plus mutant EZH2 drive tumor-associated hypertrimethylation of lysine 27 on histone $\mathrm{H} 3$ (H3K27) in human B-cell lymphomas. Proc Natl Acad Sci U S A 2010, 107:20980-20985.

28. Wu G, Broniscer A, McEachron TA, Lu C, Paugh BS, Becksfort J, Qu C, Ding L, Huether R, Parker M, Zhang J, Gajjar A, Dyer MA, Mullighan CG, Gilbertson RJ, Mardis ER, Wilson RK, Downing JR, Ellison DW, Zhang J, Baker SJ, St. Jude Children's Research Hospital-Washington University Pediatric Cancer Genome Project: Somatic histone $\mathrm{H} 3$ alterations in pediatric diffuse intrinsic pontine gliomas and non-brainstem glioblastomas. Nat Genet 2012, 44:251-253.

29. Lewis PW, Muller MM, Koletsky MS, Cordero F, Lin S, Banaszynski LA, Garcia BA, Muir TW, Becher OJ, Allis CD: Inhibition of PRC2 activity by a gain-of-function $\mathrm{H} 3$ mutation found in pediatric glioblastoma. Science 2013, 340:857-861.

30. Davies H, Bignell GR, Cox C, Stephens P, Edkins S, Clegg S, Teague J, Woffendin H, Garnett MJ, Bottomley W, Davis N, Dicks E, Ewing R, Floyd Y, Gray K, Hall S, Hawes R, Hughes J, Kosmidou V, Menzies A, Mould C, Parker A, Stevens C, Watt S, Hooper S, Wilson R, Jayatilake H, Gusterson BA, Cooper C, Shipley J, et al: Mutations of the BRAF gene in human cancer. Nature 2002, 417:949-954.

31. Fontebasso AM, Schwartzentruber J, Khuong-Quang DA, Liu XY, Sturm D, Korshunov A, Jones DT, Witt H, Kool M, Albrecht S, Fleming A, Hadjadj D, Busche S, Lepage P, Montpetit A, Staffa A, Gerges N, Zakrewska M, Zakrewski K, Liberski PP, Hauser P, Garami M, Klekner A, Bognar L, Zadeh G, Faury D, Pfister SM, Jabado N, Majewski J: Mutations in SETD2 and genes affecting histone H3K36 methylation target hemispheric high-grade gliomas. Acta Neuropathol 2013, 125:659-669.

32. Sturm D, Bender $S$, Jones DT, Lichter P, Grill J, Becher O, Hawkins $C$, Majewski J, Jones C, Costello JF, lavarone A, Aldape K, Brennan CW, Jabado N, Pfister SM: Paediatric and adult glioblastoma: multiform (epi) genomic culprits emerge. Nat Rev Cancer 2014, 14:92-107.

33. Brennan CW, Verhaak RG, McKenna A, Campos B, Noushmehr H, Salama SR, Zheng S, Chakravarty D, Sanborn JZ, Berman SH, Beroukhim R, Bernard B, Wu CJ, Genovese G, Shmulevich I, Barnholtz-Sloan J, Zou L, Vegesna R, Shukla SA, Ciriello G, Yung WK, Zhang W, Sougnez C, Mikkelsen T, Aldape K, Bigner DD, Van Meir EG, Prados M, Sloan A, Black KL, et al: The somatic genomic landscape of glioblastoma. Cell 2013, 155:462-477.

34. Killela PJ, Reitman ZJ, Jiao Y, Bettegowda C, Agrawal N, Diaz LA Jr, Friedman AH, Gallia GL, Giovanella BC, Grollman AP, He TC, He Y, Hruban RH, Jallo Gl, Mandahi N, Meeker AK, Mertens F, Netto GJ, Rasheed BA, Riggins GJ, Rosenquist TA, Schiffman M, Shih IM, Theodorescu D, Torbenson MS,
Velculescu VE, Wang TL, Wentzensen N, Wood LD, Zhang M et al: TERT promoter mutations occur frequently in gliomas and a subset of tumors derived from cells with low rates of self-renewal. Proc Natl Acad Sci U S A 2013, 110:6021-6026.

35. Goldberg AD, Banaszynski LA, Noh KM, Lewis PW, Elsaesser SJ, Stadler S, Dewell S, Law M, Guo X, Li X, Wen D, Chapgier A, Dekelver RC, Miller JC, Lee YL, Boydston EA, Holmes MC, Gregory PD, Greally JM, Rafii S, Yang C, Scambler PJ, Garrick D, Gibbons RJ, Higgs DR, Cristea IM, Urnov FD, Zheng D, Allis DC: Distinct factors control histone variant $\mathrm{H} 3.3$ localization at specific genomic regions. Cell 2010, 140:678-691.

36. Heaphy CM, de Wilde RF, Jiao Y, Klein AP, Edil BH, Shi C, Bettegowda C, Rodriguez FJ, Eberhart CG, Hebbar S, Offerhaus GJ, McLendon R, Rasheed BA, He Y, Yan H, Bigner DD, Oba-Shinjo SM, Marie SK, Riggins GJ, Kinzler KW, Vogelstein B, Hruban RH, Maitra A, Papadopoulos N, Meeker AK: Altered telomeres in tumors with ATRX and DAXX mutations. Science 2011, 333:425.

37. Chen YJ, Hakin-Smith V, Teo M, Xinarianos GE, Jellinek DA, Carroll T, McDowell D, MacFarlane MR, Boet R, Baguley BC, Braithwaite AW, Reddel RR, Royds JA: Association of mutant TP53 with alternative lengthening of telomeres and favorable prognosis in glioma. Cancer Res 2006, 66:6473-6476.

38. Lee CJ, Chan WI, Cheung M, Cheng YC, Appleby VJ, Orme AT: CIC, a member of a novel subfamily of the HMG-box superfamily, is transiently expressed in developing granule neurons. Brain Res Mol Brain Res 2002, 106:151-156.

39. Burgess RJ, Zhang Z: Histone chaperones in nucleosome assembly and human disease. Nat Struct Mol Biol 2013, 20:14-22.

40. Skene PJ, Henikoff S: Histone variants in pluripotency and disease. Development 2013, 140:2513-2524.

41. Kuo AJ, Song J, Cheung P, Ishibe-Murakami S, Yamazoe S, Chen JK, Patel DJ, Gozani O: The BAH domain of ORC1 links H4K20me2 to DNA replication licensing and Meier-Gorlin syndrome. Nature 2012, 484:115-119.

42. Jeltsch A: Reading and writing DNA methylation. Nat Struct Mol Biol 2008, 15:1003-1004

43. Kato T, Sato N, Hayama S, Yamabuki T, Ito T, Miyamoto M, Kondo S, Nakamura Y, Daigo Y: Activation of Holliday junction recognizing protein involved in the chromosomal stability and immortality of cancer cells. Cancer Res 2007, 67:8544-8553.

44. Valente V, Serafim RB, de Oliveira LC, Adorni FS, Torrieri R, Tirapelli DP, Espreafico EM, Oba-Shinjo SM, Marie SK, Paco-Larson ML, Carlotti CG Jr: Modulation of HJURP (Holliday Junction-Recognizing Protein) levels is correlated with glioblastoma cells survival. PLoS One 2013, 8:e62200

45. Hu Z, Huang G, Sadanandam A, Gu S, Lenburg ME, Pai M, Bayani N, Blakely EA, Gray JW, Mao JH: The expression level of HJURP has an independent prognostic impact and predicts the sensitivity to radiotherapy in breast cancer. Breast Cancer Res 2010, 12:R18.

46. Li F, Mao G, Tong D, Huang J, Gu L, Yang W, Li GM: The histone mark H3K36me3 regulates human DNA mismatch repair through its interaction with MutSalpha. Cell 2013, 153:590-600.

47. Simon JM, Hacker KE, Singh D, Brannon AR, Parker JS, Weiser M, Ho TH, Kuan PF, Jonasch E, Furey TS, Prins JF, Lieb JD, Rathmell WK, Davis IJ: Variation in chromatin accessibility in human kidney cancer links H3K36 methyltransferase loss with widespread RNA processing defects. Genome Res 2014, 24:241-250.

48. Fnu S, Williamson EA, De Haro LP, Brenneman M, Wray J, Shaheen M, Radhakrishnan K, Lee SH, Nickoloff JA, Hromas R: Methylation of histone $\mathrm{H} 3$ lysine 36 enhances DNA repair by nonhomologous end-joining. Proc Natl Acad Sci U S A 2011, 108:540-545.

49. Park JH, Park EJ, Lee HS, Kim SJ, Hur SK, Imbalzano AN, Kwon J: Mammalian SWI/SNF complexes facilitate DNA double-strand break repair by promoting gamma-H2AX induction. EMBO J 2006, 25:3986-3997.

50. Schuster-Bockler B, Lehner B: Chromatin organization is a major influence on regional mutation rates in human cancer cells. Nature 2012, 488:504-507.

51. Beroukhim R, Getz G, Nghiemphu L, Barretina J, Hsueh T, Linhart D, Vivanco I, Lee JC, Huang JH, Alexander S, Du J, Kau T, Thomas RK, Shah K, Soto H, Perner S, Prensner J, Debiasi RM, Demichelis F, Hatton C, Rubin MA, Garraway LA, Nelson SF, Liau L, Mischel PS, Cloughesy TF, Meyerson M, Golub TA, Lander ES, Mellinghoff IK, et al: Assessing the significance of 
chromosomal aberrations in cancer: methodology and application to glioma. Proc Natl Acad Sci U S A 2007, 104:20007-20012.

52. Eifert C, Powers RS: From cancer genomes to oncogenic drivers, tumour dependencies and therapeutic targets. Nat Rev Cancer 2012, 12:572-578

53. Rodriguez-Paredes M, Martinez de Paz A, Simo-Riudalbas L, Sayols S Moutinho C, Moran S, Villanueva A, Vazquez-Cedeira M, Lazo PA, Carneiro F, Moura CS, Vieira J, Teixeira MR, Esteller M: Gene amplification of the histone methyltransferase SETDB1 contributes to human lung tumorigenesis. Oncogene 2014, 33:2807-2813.

54. Garcia MJ, Pole JC, Chin SF, Teschendorff A, Naderi A, Ozdag H, Vias M, Kranjac T, Subkhankulova T, Paish C, Ellis I, Brenton JD, Edwards PA, Caldas C: A 1 Mb minimal amplicon at 8p11-12 in breast cancer identifies new candidate oncogenes. Oncogene 2005, 24:5235-5245.

55. Yang ZQ, Liu G, Bollig-Fischer A, Giroux CN, Ethier SP: Transforming properties of 8p11-12 amplified genes in human breast cancer. Cancer Res 2010, 70:8487-8497.

56. Qian J, Massion PP: Role of chromosome $3 q$ amplification in lung cancer. J Thorac Oncol 2008, 3:212-215.

57. Wang J, Qian J, Hoeksema MD, Zou Y, Espinosa AV, Rahman SM, Zhang B, Massion PP: Integrative genomics analysis identifies candidate drivers at 3q26-29 amplicon in squamous cell carcinoma of the lung. Clin Cancer Res 2013, 19:5580-5590.

58. Comtesse N, Keller A, Diesinger I, Bauer C, Kayser K, Huwer H, Lenhof HP, Meese E: Frequent overexpression of the genes FXR1, CLAPM1 and EIF4G located on amplicon 3q26-27 in squamous cell carcinoma of the lung. Int J Cancer 2007, 120:2538-2544.

59. Dalgliesh GL, Furge K, Greenman C, Chen L, Bignell G, Butler A, Davies H, Edkins S, Hardy C, Latimer C, Teague J, Andrews J, Barthorpe S, Beare D, Buck G, Campbell PJ, Forbes S, Jia M, Jones D, Knott H, Kok CY, Lau KW, Leroy C, Lin ML, McBride DJ, Maddison M, Maguire S, McLay K, Menzies A, Mironenko T, et al: Systematic sequencing of renal carcinoma reveals inactivation of histone modifying genes. Nature 2010, 463:360-363.

60. Le Gallo M, O'Hara AJ, Rudd ML, Urick ME, Hansen NF, O'Neil NJ, Price JC, Zhang S, England BM, Godwin AK, Sgroi DC, NIH Intramural Sequencing Center (NISC) Comparative Sequencing Program, Hieter P, Mullikin JC, Merino MJ, Bell DW: Exome sequencing of serous endometrial tumors identifies recurrent somatic mutations in chromatin-remodeling and ubiquitin ligase complex genes. Nat Genet 2012, 44:1310-1315.

61. Morin RD, Mendez-Lago M, Mungall AJ, Goya R, Mungall KL, Corbett RD, Johnson NA, Severson TM, Chiu R, Field M, Jackman S, Krzywinski M, Scott DW, Trinh DL, Tamura-Wells J, Li S, Firme MR, Rogic S, Griffith M, Chan S, Yakovenko O, Meyer IM, Zhao EY, Smailus D, Moksa M, Chittaranjan S, Rimsza L, Brooks-Wilson A, Spinelli JJ, Ben-Neriah S, et al: Frequent mutation of histone-modifying genes in non-Hodgkin lymphoma. Nature 2011, 476:298-303.

62. Zhou WW, Goren A, Bernstein BE: Charting histone modifications and the functional organization of mammalian genomes. Nat Rev Genet 2011, $12: 7-18$.

63. Daigle SR, Olhava EJ, Therkelsen CA, Basavapathruni A, Jin L, Boriack-Sjodin PA, Allain CJ, Klaus CR, Raimondi A, Scott MP, Waters NJ, Chesworth R, Moyer MP, Copeland RA, Richon VM, Pollock RM: Potent inhibition of DOT1L as treatment for MLL-fusion leukemia. Blood 2013, 122:1017-1025.

64. Rohle D, Popovici-Muller J, Palaskas N, Turcan S, Grommes C, Campos C, Tsoi J, Clark O, Oldrini B, Komisopoulou E, Kunii K, Pedraza A, Schalm S, Silverman L, Miller A, Wang F, Yang H, Chen Y, Kernytsky A, Rosenblum MK, Liu W, Biller SA, Su SM, Brennan CW, Chan TA, Graeber TG, Yen KE, Mellinghoff IK: An inhibitor of mutant IDH1 delays growth and promotes differentiation of glioma cells. Science 2013, 340:626-630.

65. Lawrence MS, Stojanov P, Polak P, Kryukov GV, Cibulskis K, Sivachenko A, Carter SL, Stewart C, Mermel CH, Roberts SA, Kiezun A, Hammerman PS, McKenna A, Drier Y, Zou L, Ramos AH, Pugh TJ, Stransky N, Helman E, Kim J, Sougnez C, Ambrogio L, Nickerson E, Shefler E, Cortes ML, Auclair D, Saksena G, Voet D, Noble M, DiCara D, et al: Mutational heterogeneity in cancer and the search for new cancer-associated genes. Nature 2013, 499:214-218.

66. Mermel CH, Schumacher SE, Hill B, Meyerson ML, Beroukhim R, Getz G: GISTIC2.0 facilitates sensitive and confident localization of the targets of focal somatic copy-number alteration in human cancers. Genome Biol 2011, 12:R41.
67. Bland JM, Altman DG: Statistics notes. The odds ratio. BMJ 2000, 320:1468.

68. Wang K, Singh D, Zeng Z, Coleman SJ, Huang Y, Savich GL, He X, Mieczkowski P, Grimm SA, Perou CM, MacLeod JN, Chiang DY, Prins JF, Liu J: MapSplice: accurate mapping of RNA-seq reads for splice junction discovery. Nucleic Acids Res 2010, 38:e178.

69. Shah MA, Denton EL, Liu L, Schapira M: ChromoHub V2: cancer genomics. Bioinformatics 2014, 30:590-592.

doi:10.1186/1756-8935-7-29

Cite this article as: Shah et al:: A global assessment of cancer genomic alterations in epigenetic mechanisms. Epigenetics \& Chromatin 2014 7:29.

\section{Submit your next manuscript to BioMed Central and take full advantage of:}

- Convenient online submission

- Thorough peer review

- No space constraints or color figure charges

- Immediate publication on acceptance

- Inclusion in PubMed, CAS, Scopus and Google Scholar

- Research which is freely available for redistribution

Submit your manuscript at www.biomedcentral.com/submit
C Biomed Central 